PREHOSPITAL CARE

\title{
Retrospective study into the delivery of telephone cardiopulmonary resuscitation to "999" callers
}

\section{A Heward, R T Donohoe, M Whitbread}

Background: Cardiopulmonary resuscitation (CPR) is an essential part of the chain of survival, with early administration directly affecting the patient's chance of survival. Prearrival telephone CPR instructions provide callers who have no CPR training on how to undertake this intervention. With the emergency medical dispatcher unable to see the caller or the patient, it is possible that problems will arise, presenting barriers, that stop the caller undertaking effective CPR.

Objective: To examine how commonly barriers to telephone CPR occur and whether this affects the time it takes to perform the intervention.

Method: A retrospective quantitative analysis was undertaken using a convenience sample of 100 emergency calls. Calls were identified in the emergency control room as cardiac arrests and confirmed by the responding paramedics as cardiac arrests. The calls were listened to, established if CPR instructions were given, if the instructions were followed, if anything hindered the instructions undertaken, and the time taken to reach key points.

Findings: 18 cases had bystander CPR administered. An additional 56 of cases had CPR instructions provided but "barriers" in $49 \%(n=27)$ hindered the effectiveness of these. The median time to recognition of cardiac arrest was 40 seconds, with time to first ventilation being $4 \mathrm{~min} 10 \mathrm{~s}$ and time to first compression $5 \mathrm{~min} 30 \mathrm{~s}$. These times were notably higher in those cases where a barrier to effective telephone CPR existed.

Conclusions: Barriers to undertaking telephone CPR occurred with a high degree of frequency. These barriers affect the ability of the caller to perform rapid and effective telephone CPR.


ardiopulmonary resuscitation (CPR) is an essential part of the chain of survival, greatly increasing patients' chances of survival from out of hospital cardiac arrest. ${ }^{1-3}$ Unfortunately, it has been shown that those with a patient during their time of need seldom perform $\mathrm{CPR},{ }^{45}$ and those that do carry it out, perform it ineffectively. ${ }^{6}$

Currently, the London Ambulance Service Trust Service uses the Advanced Medical Priority Dispatch System (AMPDS) to provide callers with protocol led telephone CPR (t-CPR) instructions helping them perform the potentially lifesaving intervention of CPR.

Evidence suggests that $\mathrm{t}-\mathrm{CPR}$ is more effective than not providing any CPR. ${ }^{35}$ Yet, anecdotal reports from a number of ambulance services suggest many callers do not follow the instructions they are being given finding problems in undertaking and performing the intervention. ${ }^{6}$

The aim of this study is to examine how frequently barriers to t-CPR occur and whether these affect the time it takes to perform the intervention.

\section{METHODS}

To undertake this retrospective, quantitative study; a convenience sample of 100 emergency calls was selected. Each of these calls had to fulfil entry criteria:
(1) The emergency call was triaged, through the systematic questioning process of AMPDS, as cardiac arrest.

(2) Be recorded by the responding ambulance crew as being a cardiac arrest. All cases in this study were actively resuscitated by the responding ambulance crew, thus eliminating cases that were either inappropriately triaged (not cardiac arrest) or cases where the patient was beyond resuscitation.

AMPDS is a structured call taking process with a standardised process of quality assurance. Individual compliance for each case was not measured but across the study period compliance was in excess of that required for Accredited Centre of Excellence Standards. ${ }^{7}$

During this process the control room documentation and patient report form for each case was obtained and reviewed, to present a complete picture of the call history.

For each of these cases the timings of the following key tasks were measured;

(1) time taken from the start of the call to the identification of the situation being a cardiac arrest by either the EMD or the caller,

(2) time taken from the start of the call to the first ventilation being administered,

(3) time to the administration of the first compression,

Each call was assessed for any indication of a "barrier" preventing the effective undertaking of the t-CPR instructions. The term "barrier" is a subjective term but was used to describe anything that the authors felt affected the ability of the caller to perform t-CPR or the emergency medical dispatchers' (EMDs) ability to provide the instructions to the caller. This includes areas such as emotional callers, difficulty in moving the patient to a suitable location, and language problems.

Descriptive statistics have been used to present the findings of this study.

Table 1 Reason why t-CPR instructions were not given

\begin{tabular}{ll}
\hline Reason for not receiving T-CPR & Breakdown \\
\hline Caller knew CPR & $n=18$ \\
Caller thought the patient was dead & $n=6$ \\
Caller didn't want to undertake the procedure & $n=2$ \\
3rd/4th party caller & $n=4$ \\
CPR instructions not offered & $n=1$ \\
Language problems & $n=1$ \\
Can't move caller into position & $n=2$ \\
Other & $n=10$
\end{tabular}

Abbreviations: CPR, cardiopulmonary resuscitation; EMD, emergency medical dispatcher; $\mathrm{t}-\mathrm{CPR}$, telephone cardiopulmonary resuscitation; 


\begin{tabular}{|c|c|c|c|c|}
\hline Key task & $\begin{array}{l}\text { No barrier } \\
\text { (median) }\end{array}$ & Interquartile range & $\begin{array}{l}\text { Barrier } \\
\text { (median) }\end{array}$ & Interquartile range \\
\hline $\begin{array}{l}\text { Recognition of } \\
\text { cardiac arrest }\end{array}$ & $20 \mathrm{~s}$ & $0 s-40 s$ & $1 \mathrm{~min} 30 \mathrm{~s}$ & $30 s-2 \min 20 s$ \\
\hline & $2 \min 00 \mathrm{~s}$ & $1 \min 30 s-2 \min 20 s$ & $6 \min 00 \mathrm{~s}$ & $4 \min 15 s-7 \min 35 s$ \\
\hline $\begin{array}{l}\text { Time to first } \\
\text { compression }\end{array}$ & $3 \min 05 s$ & $2 \min 22 s-4 \min 26 s$ & $7 \mathrm{~min} 10 \mathrm{~s}$ & $6 \min 00 s-8 \min 30 s$ \\
\hline
\end{tabular}

\section{RESULTS}

\section{Administering CPR}

From the 100 cases studied, 56 callers were given and reported following $\mathrm{t}-\mathrm{CPR}$ instructions. Reasons t-CPR instructions were not followed varied (table 1). In total 74 of the 100 patients received CPR subsequent to their cardiac arrest and before the responding ambulance crew arriving on scene.

\section{Timings}

The median time to achieving the identification of cardiac arrest and then undertake the key task of administering artificial ventilations and chest compressions was 40 seconds, $4 \mathrm{~min} 10 \mathrm{~s}$, and $5 \mathrm{~m} 30 \mathrm{~s}$ respectively.

\section{Barriers}

"Barriers" occurred in 49\% of the calls where t-CPR was provided. A notable difference existed in the time it took to reach the key tasks between callers where a barrier did not exist and those were a barrier did (table 2).

\section{DISCUSSION}

This study supports previous work indicating that the frequency of bystander initiated CPR is normally comparatively low, but highlights the fact that the provision of t-CPR may dramatically improve this frequency.

In just under $50 \%$ of cases where t-CPR instructions were given, there were barriers that affected the effective delivery of instructions. The barriers lengthened the time it took to administer CPR, so it is probable that this would affect the effectiveness of $\mathrm{t}$-CPR on patients in cardiac arrest.

Currently, t-CPR instructions as provided by AMPDS are scripted instructions that must be read verbatim, ${ }^{8}$ as yet no specific CPR/Basic Life Support (BLS) instructions have been designed with dispatch life support in mind. ${ }^{8}$ Consideration should be given to relaxing or developing this strict policy to allow EMDs and callers to overcome these barriers.

The greatest delay, across all the barriers, seems to be in the time before administering ventilations. This is consistent with previous findings identifying that apprehension and reluctance is often displayed by bystanders when mouth to mouth contact is required. ${ }^{9}$

In relation to this point, both $\mathrm{Rea}^{3}$ and Hallstrom ${ }^{5}$ indicate that compression only CPR is an effective and sensible practice to adapt, with the outcomes as good as conventional t-CPR. This means that the time taken delivering CPR may be drastically reduced presenting a faster collapse to intervention time. This sounds like a simple solution until it is considered that this evidence originates from studies covering areas renown for having effective community responder schemes, with response times of minutes and although higher levels of oxygen may be delivered during the first two minutes of compression only CPR and values similar to conventional CPR reported between the third and fourth minutes, after this the values then continue to drop. ${ }^{10}$ Therefore, is compression only CPR a practical option for areas where responses times are routinely outside the four minute window of collapse to responder arrival.

The solution to t-CPR problems is not as clear cut as first imagined. Further work is needed to both look at the barriers to CPR and understand how to reduce them and secondly, to undertake research into whether compression only CPR would be a viable proposition in an ambulance service with response time beyond the four minute benchmark, or whether a solution laying between conventional t-CPR and compression only t-CPR needs to be found. Until this we are left in something of a quandary.

\section{Contributions}

Andy Heward and Mark Whitbread conceived this study and reviewed the calls. Andy Heward managed the data collection process, constructed the data collection tool, and wrote this paper. Rachael Donohoe provided assistance writing this paper.

\section{Authors' affiliations}

A Heward, R T Donohoe, M Whitbread, London Ambulance Service NHS Trust, London, UK

Funding: none.

Conflicts of interest: none declared.

Correspondence to: Mr A Heward, London Ambulance Service NHS Trust, 220 Waterloo Road, London SE1 8SD, UK; andy.heward@londamb.nhs.uk

Accepted for publication 19 November 2003

\section{REFERENCES}

1 Thomson RG, Hallstrom AP, Cobb LA. Bystander-initiated cardiopulmonary resuscitation in the management of ventricular fibrillation. Ann Intern Med 1979;90:737-40

2 Bang A, Biber B, Isaksson L, et al. Evaluation of dispatcher-assisted cardiopulmonary resuscitation. Eur J Emerg Med 1999:6:175-83.

3 Rea TD, Eisenburg MS, Culley LL, et al. Dispatcher assisted cardiopulmonary resuscitation and survival in cardiac arrest. Circulation 2001; 104:2513-16.

4 Culley LL, Clark JJ, Eisenburg MS, et al. Dispatcher-assisted telephone CPR: common themes delays and time standards for delivery. Ann Emerg Med 1991;20:362-6.

5 Hallstrom AP, Crobb L, Johnson E, et al. Cardiopulmonary resuscitation by chest compression alone or with mouth to mouth ventilation. N Engl J Med 2000;342:1546-53.

6 Belgian Cerebral Resuscitation Study Group. Quality and efficiency of bystander CPR. Resuscitation 1993;26:47-52.

7 National Academy of Emergency Dispatch. EMD-Q. Salt Lake City: Priority Press, 2000.

8 Clawson J, Dernocoeur KB. Principles of emergency medical dispatch. Salt Lake City: Priority Press, 2000.

9 Hew P, Brenner B, Kaufman J. Reluctance of paramedics and emergency medical technicians to perform mouth-to-mouth resuscitation. J Emerg Med 1997; 15:279-84.

10 Turner I, Turner S, Anderson V. Does the compression to ventilation ratio affect the quality of CPR: a simulation study. Resuscitation 2002;52:55-62. 